\title{
The Prevalence of Tongue Lesions in Libyan Adult Patients
}

\author{
Sujata.M.Byahatti ${ }^{1}$, Mohammed. S. H. Ingafou ${ }^{2}$
}

${ }^{1}$ BDS, MDS, Senior Lecturer, Department of Oral medicine, diagnosis and radiology at Faculty of Dentistry, Garyounis University, and Benghazi, Libya.

${ }^{2}$ M.Sc, PhD, Professor, Department of Oral medicine, diagnosis and radiology at Faculty of Dentistry, Garyounis University, and Benghazi, Libya.

Correspondence:

Plot No 49, Sector No 9, Malamaruthi Extension,

Belgaum-590016, KARNATAKA, INDIA

Email: sujatabyahatti@rediffmail.com

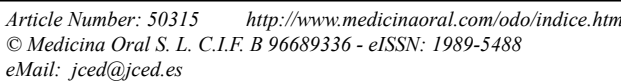

\begin{abstract}
This is the first ever-detailed study of tongue diseases in Libyan population, where the tongue conditions found in 320 patients $(9.2 \%)$ of 3,460 consecutive patients screened in the department of Oral Medicine and Oral Diagnosis at faculty of dentistry, Benghazi Libya. Both sexes were affected almost equally and only 25 patients were aware of their tongue disease. Forty patients had one or more systemic illness, 34 of them was on regular medications. Fissured tongue was the most prevalent condition, as it has been found in 155(48.4\%) patients, depapillated tongue in $82(25.6 \%)$ patients and geographic tongue in 55(17.2\%) patients, other disease conditions were found in a lesser number of patients. Fifty-four patients had painful tongue conditions; other complaints included malodor, speech interferences or swallowing difficulties. Most conditions were confined to the tongue and in more than $90 \%$, there had been involvement of the dorsum of the tongue. Fortunately, most tongue conditions can easily be diagnosed on clinical grounds by any experienced clinician, hence, the histopathological examination and other investigations are needed in only few cases. There is a wide variation in the prevalence of most of tongue diseases worldwide due to the lack of uniformity in criteria of the studies. Thus, more studies are needed in this regard.
\end{abstract}

Key words: Tongue disorders, Libyan patients, Clinical study, oral diseases. 


\section{Introduction}

Tongue is the most accessible organ of the oral cavity. Traditionally, tongue lesions have been considered disorders of primary concern regarding oral and general health (1). Tongue is essentially muscular complex organ covered by epithelium and performs many functions like suckling, swallowing, phonation and perception of sensations including taste characteristics, thermal changes, pain stimuli and general sensations and helps in jaw development (2). Such functions can be affected by the changes in oral environment and the extreme alterations in thermal, mechanical and microbial factors.

The real frequency of different tongue diseases in different ethnic groups is speculative, since well-designed population epidemiologic studies have not been performed or are inconclusive, nevertheless, in many instances, the clinical experience allows for gross estimates of disease prevalence (3). The occurrence of different tongue lesions has been abundantly studied previously where it has been noticed that tongue can be targeted by a wide range of pathological conditions, such changes can be confined to the tongue only or the tongue may be a part of widespread oral involvement. As the clinical appearance of tongue conditions varies greatly, the vast majority of tongue lesions are of local etiology. The recognition of tongue lesions may be helpful in the early diagnosis of some systemic diseases. This study is designed to provide information on the prevalence of the most frequently encountered tongue lesions in general dental practice; hopefully it would be useful for further research.

\section{Material and Methods}

This study describes the clinical characteristics of tongue diseases found in 320 patients of 3,460 routine consecutive patients screened for tongue changes at the department of Oral Diagnosis and Oral Medicine, faculty dentistry of Garyounis University in the period between July 2007 and February 2008

All the patients were examined by both the authors (who are specialists in Oral Medicine). The clinical examination of the oral mucosa and tongue was performed according to World Health Organization (WHO) guidelines. At the patient interview, a record was done for demographic data, general health, medication intake and allergies. Oral health-care practices at home as well as the smoking and alcohol drinking habits of the patient were also recorded to determine their effects on the tongue. Every patient was subjected to a through clinical examination by standard methods of examination of the oral cavity and particularly the tongue. Examination of the tongue included surface changes, its size and movements, and the presence of specific mucosal lesions.

Ninety two percent of the patients with tongue conditions came to our department for symptoms unrelated to the tongue. These included dental pain, decayed teeth, bleeding gums or tooth mobility. About 25 patients $(8 \%)$ have complaints related to the tongue such as painful lingual swelling, ulceration, taste alteration or burning sensation. The diagnosis was based up on clinical findings alone in 292 patients, while in 28 cases, further histopathological and laboratory investigations were carried out to confirm the clinical diagnosis.

Those conditions involved the tongue as part of systemic disease or the entire oral cavities are listed separately from those confined to the tongue only. Further analysis was done for the most frequent tongue conditions in this group of patients (namely fissured tongue, geographic tongue and hairy tongue).

\section{Results}

The study group comprised 320 patients with tongue disease constituting $9.2 \%$ of the examined population, $($ male $=173$; male $=147)$. Their age ranged from 14 to 73 years (median age was 33 years) (Fig.1). Most of these patients live in the city of Benghazi, with different socioeconomic levels and occupations. Sixty-seven males were smokers and forty patients suffered from one or more systemic diseases (mainly diabetes mellitus and hypertension or both). Thirty-four patients were on regular medication for various reasons at the time of interview (Table 1).

\begin{tabular}{|l|l|}
\hline Total number of patients & $\mathbf{3 2 0}$ \\
\hline Males & $147(46 \%)$ \\
\hline Females & $173(54 \%)$ \\
\hline Median age & 33 years \\
\hline Age range & $14-73$ years \\
\hline Number of smokers & 67 (all males) \\
\hline Number of pts with tongue complaints & 25 \\
\hline Patients with systemic diseases & 40 \\
\hline
\end{tabular}

Table 1. General Demographic data of the study group

Fissured tongue was the most common condition as it has been found in $155(48.4 \%)$ patients while tongue depapillation (focal and generalized) was seen in 82 (25.6\%) patients, geographic tongue in $55(17.2 \%)$ patients, bifid tongue in $20(6.3 \%)$ patients and hairy tongue in $14(4.4 \%)$ patients. Miscellaneous tongue conditions were seen in only few patients and more than one tongue condition co-existed in several patients as shown in Table 2.

Twenty-five (7\%) patients were actually made aware of the changes in their own tongues derived by pain, gross swelling or disturbed tongue functions such as phonation or swallowing. However, the majority of tongue conditions were asymptomatic except in 54 cases presented with burning sensation (19 patients), taste alteration (9 patients), speech difficulties (14 patients), swallowing difficulties (14 patients), and dry mouth (9 patients) as illustrated in Fig. 1. Those conditions which accompa- 


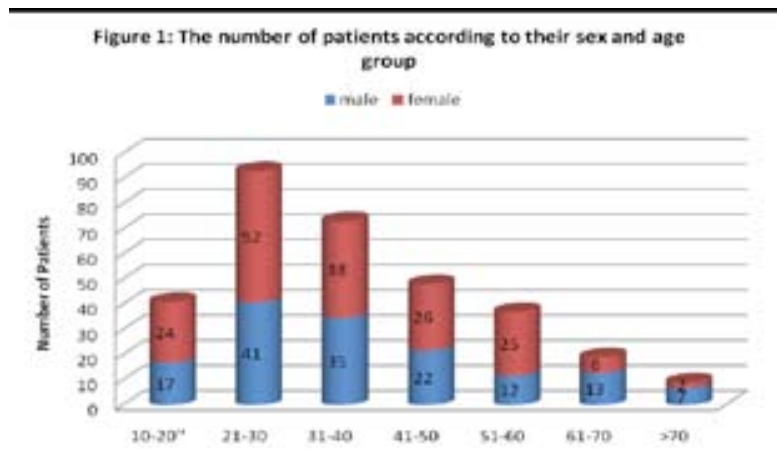

Fig. 1. The number of patients acording to their sex and age group
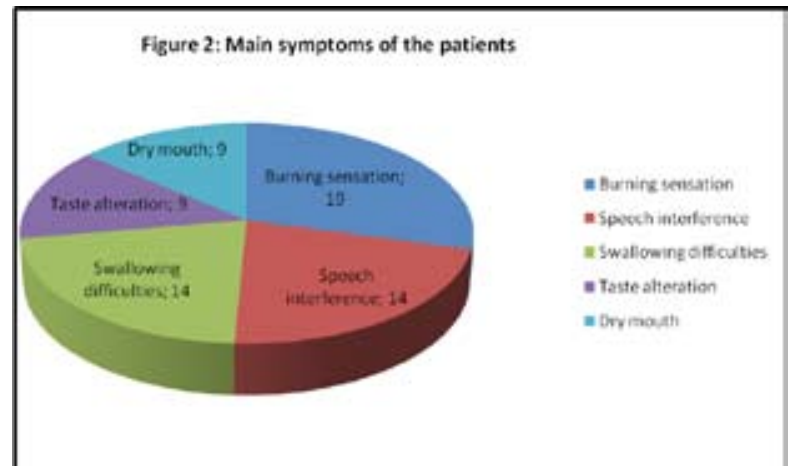

Fig. 2. Main symptoms of the patients

nied by pain in this group of patients are listed in Table 3.

Nearly $93 \%$ of the cases were confined to the tongue only. Simultaneous extraglossal involvement was mostly seen on the buccal mucosa, labial mucosa, palate, gingiva and floor of the mouth respectively (Fig. 2). Ninety per cent of the lesions involved the dorsum, the lateral borders in 24 cases, ventral surface in 5 cases, while the posterior one third of the tongue was involved in 2 cases only (Fig. 3).

Tongue fissuring of plicated, cerebreform, or scrotal configuration was detected in both sexes of all age groups and associated with geographic tongue in $21(42 \%)$ patients and with pain symptoms in 25 patients and malo-

\begin{tabular}{|l|l|}
\hline Disease & Number of patients \\
\hline Diabetes mellitus & 14 \\
\hline Hypertension & 12 \\
\hline Rheumatism & 8 \\
\hline Thyroid problems & 3 \\
\hline Asthma & 3 \\
\hline Anemia & 2 \\
\hline malignancy & 2 \\
\hline Sjogren's syndrome & 2 \\
\hline $\begin{array}{l}\text { *Many patients have more than one disease. ** 34 patients on regular } \\
\text { Medication }\end{array}$
\end{tabular}

Table 2. Systemic Diseases In 40 Patients In This Group*

Figure 3: Extraglossal involvement along with

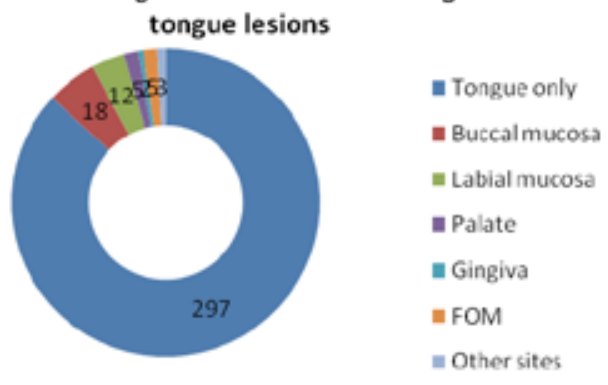

Fig. 3. Extraglossal involvement along with tongue lesions

dor in three patients. The geographic tongue was seen in 55 patients in both sexes, of all age groups. It associates with fissured tongue in 21 patients and in 10 cases; there has been pain symptoms, particularly with spicy food or lemon. Taste changes were reported by only one patient. Extraglossal geographic affections (geographic stomatitis) was detected in further three patients. A comparison of the different characteristics between fissured and geographic tongue is shown in Table 4.

Hairy tongue of different colors was detected in 14 patients. In all the cases it was asymptomatic and only one female patient was actually worried about the appearance of her tongue. The tongue was involved by lichenoid lesions in seven patients, in which there had been an ex-

\begin{tabular}{|l|c|l|c|}
\hline \multicolumn{1}{|c|}{ Condition } & No of patients (\%) & \multicolumn{1}{c|}{ Condition } & No of patients (\%) \\
\hline Fissured tongue & $155(48.4 \%)$ & White sponge nevus & $3(0.9 \%)$ \\
\hline Depapillated tongue & $82(25.6 \%)$ & Median glossitis & $2(0.6 \%)$ \\
\hline Geographic tongue & $55(17.2 \%)$ & Enlarged folait papillae & $2(0.6 \%)$ \\
\hline Clefted tongue (bifid) & $20(6.3 \%)$ & Papilloma & $2(0.6 \%)$ \\
\hline Hairy tongue & $14(4.4 \%)$ & Amalgam tattoo & $1(0.3 \%)$ \\
\hline Lichen planus & $7(2.2 \%)$ & Ankyloglossia & $1(0.3 \%)$ \\
\hline Aphthous ulceration & $5(1.6 \%)$ & Hemangioendpothelioma & $1(0.3 \%)$ \\
\hline Fibroepithelial polyp & $5(1.6 \%)$ & Herpes zoster & $1(0.3 \%)$ \\
\hline Traumatic ulcer & $5(1.6 \%)$ & Leucoplakia & $1(0.3 \%)$ \\
\hline Geographic stomatitis & $3(0.9 \%)$ & Lymphangioma & $1(0.3 \%)$ \\
\hline Hemangioma & $3(0.9 \%)$ & Radiation mucositis & $1(0.3 \%)$ \\
\hline Squamous cell carcinoma & $3(0.9 \%)$ & Pemphigus vulgaris & $1(0.3 \%)$ \\
\hline Tongue abscess & $3(0.9 \%)$ & Xerostomia & $1(0.3 \%)$ \\
\hline
\end{tabular}

Table 3. The frequency of tongue conditions in the study group 


\begin{tabular}{|l|c|}
\hline Condition & No of patients \\
\hline Benign migratory glossitis & 11 \\
\hline Depapillated tongue & 9 \\
\hline Glossodenya (no lesions seen) & 6 \\
\hline Aphthous ulcer & 5 \\
\hline Lichen planus & 5 \\
\hline Traumatic ulcer & 5 \\
\hline Atrophic candidiasis & 4 \\
\hline Tongue abscess & 3 \\
\hline Erythema multiformis & 1 \\
\hline Herpes zoster & 1 \\
\hline Median glossitis & 1 \\
\hline Mucositis & 1 \\
\hline Pemphigus vulgaris & 1 \\
\hline Sjogrens syndrome & 1 \\
\hline Total & $\mathbf{5 4}$ \\
\hline
\end{tabular}

Table 4. Tongue Conditions associated with pain symptoms

\begin{tabular}{|l|c|c|}
\hline & $\begin{array}{l}\text { Fissured } \\
\text { tongue }\end{array}$ & $\begin{array}{l}\text { Geographic } \\
\text { tongue }\end{array}$ \\
\hline No. of Patients & 155 & 55 \\
\hline Female & 83 & 26 \\
\hline Male & 72 & 29 \\
\hline Symptomatic lesion & 25 & 10 \\
\hline $\begin{array}{l}\text { Association with fissured ton- } \\
\text { gue }\end{array}$ & - & 21 \\
\hline Smokers & 12 & 10 \\
\hline Malodor & 3 & 3 \\
\hline Extraglossal lesions & - & 3 \\
\hline
\end{tabular}

Table 5. General characteristics of cases with fissured and geographic tongue

tragolssal involvement especially of the buccal mucosa in all patients.

Different kinds of tongue ulcers were seen in fifteen patients. Five of them were traumatic, the same number of patients had aphthous ulceration and 3 patients had malignant ulcers. There was one patient with pemphigus vulgaris and another one with herpes zoster.

Malodor was reported by seven patients and was associated with fissured tongue in three patients and tongue coating in five patients. A difficulty in tongue movement was experienced by two patients presented with advanced squamous cell carcinoma. Small number of cases had solitary small benign tumors, heamangiomas, or lymphangioma as shown in Table 2.

\section{Discussion}

Epidemiological studies have shown high frequency of tongue diseases among mucosal lesions of the oral cavity with variable prevalence in different parts of the world (4-8). Such variations are due to the differences in ethnic groups, sex and age of the studied samples and the use of different diagnostic criteria, methodology and

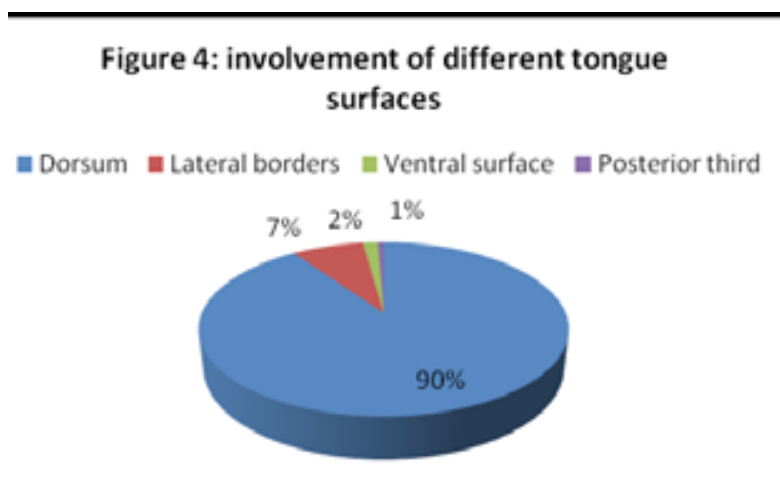

Fig. 4. Involvement of different tongue surfaces

procedures (9). Consequently, the prevalence found for each lesion varies widely among research groups (10). Tongue lesions estimated to occur in up to $18.5 \%$ of the examined individuals in different populations $(3,9)$. Furthermore, these studies estimated that only $3 \%$ of the patients are actually aware of the presence of tongue condition in their mouths, and about $5 \%$ of the patients have associating pain symptoms such as burning sensations, interferes with speech or swallowing or the inability to tolerate spicy hot food. Although the overall number of patients with tongue disease is less than that found in the above mentioned studies, the number of patients aware of their tongue condition is more and more symptomatic cases found in this study than in other previous studies. The diagnostic value of tongue changes associating with various systemic illnesses might be overestimated by some authors, keeping in mind the non-specificity of most of these changes, which may associate with many disease processes. We considered the racial pigmentation, lingual varices and coated tongue as normal variations as the majority of previous studies did; nevertheless few studies had listed these conditions among the diseases of the tongue (11-13). Similarly, the functional disorders of the tongue were not included in the list of tongue diseases; examples are tongue thrusting habit, taste disturbance or speech problems unless they are otherwise associating with organic disorders of the tongue.

Fissured tongue occurs as normal variant in less than $10 \%$ of population and probably genetically determined. Salivary hypofunction, possibly vitamin B deficiency, candidiasis and lichenoid lesions may be contributory in the development of tongue fissuring (14). Fissured tongue has been reported to be frequently associated with diabetes mellitus (13). It was found in $20 \%$ of Turkish dental out patients and was more in men than in women (1). In our study fssured tongue was the most prevalent condition, than the above mentioned studies.

Clefted or lobed tongue is sometimes used to describe a midline fissure, which is sometimes associated with pain due to accumulation of food debris and bacteria (15). In 
this study, 20 cases have clefted tongue; only two patients have pain symptoms. On the other hand, numerous authors have observed a relationship between fissured tongue and geographic tongue $(16,17)$.

Geographic tongue is among the most frequently reported tongue disease in most worldwide studies $(13,18$, 19). There is a wide variation in the prevalence of geographic tongue among different populations (especially children population) as it was $0.6 \%$ in USA, $1.6 \%$ in South Africa and $21 \%$ in Brazil $(11,12,20)$. This variation in prevalence among populations is due to different clinical criteria used. The onset of geographic tongue starts in early childhood and occasionally at puberty with a predominant presence in females (3). However, it can be diagnosed in individuals older than 40 years (10). This difference in prevalence among different age groups might indicate that genetic factors do not participate in the multifactorial etiology of geographic tongue. The lesions in geographic stomatitis (ectopic geographic tongue) are clinically and histologically similar to those normally confined to the tongue seen on other oral mucosa surfaces (21). Only three of such cases of geographic stomatitis were detected in this group of patients. Tongue depapillation is characterized by localized or extensive loss of papillae from the anterior two thirds of the dorsum of the tongue and associates with chronic trauma, nutritional deficiencies, lichen planus, xerostomia and candidiasis. In some cases, it associated with burning sensation. The depapillated areas are patchy in most of our cases may be due to local trauma mainly, rough margins of restorations, lichenoid lesions, the use of medications and chronic candidiasis. The results obtained were in accordance with other studies (1).

Hairy tongue is clinical manifestation of elongation of the filliform papillae, which is located on the dorsum of the tongue, often is a response to infections, fever, xerostomia, and some substances, such as antibiotics and tobacco. In our patients, there were 14 (4.4\%) patients with hairy tongue of different colors (white, yellow, black). Such lesions have accounted with a prevalence rate of 11.3 per cent $(1,13)$.

Median rhomboid glossitis is once thought to be a congenital abnormality. Where the possible role of Candida albicans has been stressed, as many of these observed "lesions" have been associated with candidal infection and the clinical changes disappear or are greatly improved following antifungal treatment. However, some uncertainty remains, since some of these lesions are not controlled by the use of antifungal agents (22). It is proposed that Actinomyces like Candida induces pseudoepitheliomatous hyperplasia of the mucosa of the tongue and inflammatory hyperplasia of the underlying connective tissue, resulting in the characteristically elevated lesion (23). In this study, only two patients found with this condition.
The tongue was involved by lichenoid lesions in seven patients, where plaque-like, erosive or atrophic affections seen mostly the lateral borders of the dorsum of the tongue. Lichen planus rarely confined to the tongue only without the involvement of other intraoral sites such as the buccal mucosa and the gingiva $(24,25)$.

The prevalence of ankyloglossia is between $0.1 \%$ and $3.7 \%$ in different studies $(7,26)$. There is no well-validated clinical method for establishing a diagnosis of ankyloglossia (27). Only one patient with partial ankyloglossia (tongue-tie) was found in this group of patients. White sponge nevus (WSN) is a painless, benign genetic condition, that usually seen bilaterally involving the buccal mucosae as an irregular epithelial surface keratosis accompanied by similar changes on the lateral aspects of the tongue. In this study, there were three cases of WSN with tongue involvement.

Different types of benign tumors can involve the tongue. These include lipoma, papilloma, and heamangiomas (28). In this study, all the five cases with fibroepithelial polyps of the tongue were precipitated by an obvious source of chronic irritation such as fractured amalgam, sharp edge of a tooth cusp, or bite defects. Another five cases have traumatic ulceration of the tongue caused mostly by sudden biting on the tongue. Aphthous ulceration of the tongue is listed with the painful conditions involving the tongue. Generally, all ulcers involving the tongue should carefully be examined to rule out malignancy.

In conclusion, the prevalence of tongue lesions in Libyan patients is similar to epidemiological data reported in other studies, but the lack of uniformity in the criteria adopted by many epidemiological studies makes it difficult to draw coherent conclusion about the real prevalence of tongue conditions. In general dental practice, it is the responsibility of the dentist be able to identify and differentiate oral mucosal lesions that signal an underlying systemic disease from those frequently appear in benign form. The full knowledge of the clinical presentation of different oral lesions can be life saving in some cases if an early detection and prompt referral of the patient is done in the right time.

\section{References}

1. Avcu N, Kanli A. The prevalence of tongue lesions in 5150 Turkish dental outpatients. Oral Dis. 2003;9:188-95.

2. du Toit DF. The tongue: structure and function relevant to disease and oral health. SADJ. 2003;58:375-6, 380-3.

3. Rioboo-Crespo Mdel R, Planells-del Pozo P, Rioboo-García R. Epidemiology of the most common oral mucosal diseases in children. Med Oral Patol Oral Cir Bucal. 2005; 10:376-87.

4. Axéll T. A prevalence study of oral mucosal lesions in an adult Swedish population. Odontol Revy Suppl. 1976;36:1-103.

5. Glenert U, Pindborg JJ, Andreasen JO. Tongue surface conditions of 478 residents of a large Danish rest home. Gerodontics. 1986;2:82-6.

6. Bouquot JE, Gundlach KK. Odd tongues: the prevalence of common tongue lesions in 23,616 white Americans over 35 years of age. Quintessence Int. 1986;17:719-30. 
7. Salem G, Holm SA, Fattah R, Basset S, Nasser C. Developmental oral anomalies among schoolchildren in Gizan region, Saudi Arabia. Community Dent Oral Epidemiol. 1987;15:150-1.

8. Sedano HO, Carreon Freyre I, Garza de la Garza ML, Gomar Franco CM, Grimaldo Hernandez C, Hernandez Montoya ME, et al. Clinical orodental abnormalities in Mexican children. Oral Surg Oral Med Oral Pathol. 1989;68:300-11.

9. Darwazeh AM, Pillai K. Prevalence of tongue lesions in 1013 Jordanian dental outpatients. Community Dent Oral Epidemiol. 1993;21:323-4.

10. Banoczy J, Rigo O, Albrecht M. Prevalence study of tongue lesions in a Hungarian population. Community Dent Oral Epidemiol 1993; 21:224-6.

11. Kleiman DV, Swango PA, Pndborg JJ. Epidemiology of mucosal lesions in United States schoolchildren: 1986-1987. Community Dent Oral Epidemiol. 1994; 22:243-53.

12. Bezerra S, Costa Isabel. Oral conditions in childrens from birth to 5 years: the findings of a children's dental program. J Clin Pediatr Dent 2000; 25:79-81.

13. Benevides dos Santos PJ, Ferreira C, Ferreira de Aguilar MC, Vieria do Carmo MA. Cross-sectional study of oral mucosal conditions among a central Amazonian Indian comunity, Brazil. J Oral Pathol Med 2004; 33:7-12.

14. Kullaa-Mikkonen A, Järvinen J. Effects of age, sex and salivary secretion on the human tongue surface. Gerodontics. 1988; 4(3):150-3.

15. Grushka M, Epstein JB, Gorsky M. Burning mouth syndrome. Am Fam Physician. 2002; 15; 65(4):615-20.

16. Voros Balog T, Vincze N, Benoczy J. Prevalence of tongue lesions in Hungarian children. Oral Diseases 2003; 9:84-87.

17. Shulman JD Carpenter WM. Prevalence and risk factors associated with geographic tongue among US adults. Oral Dis. 2006;12(4):381-6.

18. Redman RS. Prevalence of geographic tongue, fissured tongue, median rhomboid glossitis, and hairy tongue among 3,611 Minnesota schoolchildren. Oral Surg Oral Med Oral Pathol. 1970; 30(3):390-5.

19. Chosak A, Zadik D, Eidelman E. The prevalence of scrotal tongue and geographic tongue in 70,359 Israeli schoolchildren. Community Dent Oral Epidemiol. 1974; 2:253.

20. Arendorf TM, Van der Ross R. Oral lesions in a black pre-school South African population. Community Dent Oral Epidemiol 1996; 24:296-7.

21. Borrie F, Musthyala R, Macintyre D. Ectopic geographic tongue--a case report. Dent Update. 2007 Mar; 34(2):121-2.

22. Van der Wal N, van der Kwast WA, van der Waal I. Median rhomboid glossitis. A follow-up study of 16 patients. J Oral Med. 1986; 41(2):117-20

23. Nowak K, Szyfter W. Median rhomboid glossitis--change of inflammation origin or developmental anomaly? Otolaryngol Pol. 2005; 59(6):857-60

24. Ingafou M, Leao JC, Porter SR, Scully C. Oral lichen planus: a retrospective study of 690 British patients. Oral Dis. 2006; 12(5):463-8. 25. Seoane J, Romero MA, Varela-Centelles P, Diz-Dios P, GarciaPola MJ. Oral lichen planus: a clinical and morphometric study of oral lesions in relation to clinical presentation. Braz Dent J. 2004; 15(1):912.

26. Jorgenson RJ, Shapiro SD, Salinas CF, Levin LS. Intraoral findings and anomalies in neonates. Pediatrics. 1982 M; 69(5):577-82.

27. Chidzonga MM, Mahomva L, Marimo C. Gigantic tongue lipoma: a case report. Med Oral Patol Oral Cir Bucal. 2006; 11(5):E437-9.

28. Segal LM, Stephenson R, Dawes M, Feldman P. Prevalence, diagnosis, and treatment of ankyloglossia: methodologic review. Can Fam Physician. 2007; 53:1027-33.

\section{Acknowledgement}

We are grateful to Garyounis University's institution for research and development and for their support. 